\title{
PZT ペレットの動的微小変位測定と電気特性との関係
}

\author{
酒井武信・河本 洋 \\ (財)ファインセラミックスセンター，456 名古屋市熱田区六野 2-4-1
}

\section{Relationship between Electrical Properties and Dynamic Displacement of Piezoelectric Pellets}

Takenobu SAKAI and Hiroshi KAWAMOTO

Japan Fine Ceramics Center, 2-4-1, Mutsuno, Atsuta-ku, Nagoya-shi 456

\begin{abstract}
Piezoelectric ceramics such as lead zirconate titanate (PZT) have found wide applications because of their excellent piezoelectric properties. We have developed a dynamic displacement measurement system for PZT pellet with the resolution of $1 / 100 \mu \mathrm{m}$, under the conditions which is same one for stack actuator, i.e., several voltage, from 6 to $100 \mathrm{~Hz}$ of frequency, from 0 to $27.7 \mathrm{MPa}$ of pre-load. The relationships between electrical and displacement properties were studied and discussed using the domain switching properties which is influenced by voltage and pre-load.

[Received May 19, 1997; Accepted August 7, 1997]
\end{abstract}

Key-words : Piezoelectric ceramics, Displacement, Domain switching, Actuator

\section{1. 緒 言}

チタン酸ジルコン酸鉛（PZT） を用いたアクチュエーター は，高速応答・低消費電力等の特長があり高度制御システムへ の応用が期待されている。特に，ペレット状薄板を複数枚積み 重ねた積層アクチュエーターは，高荷重下で大きな仕事量を発 生できるために各種の応用研究がされている1) 4).しかし， 荷重の大きさ・駆動電圧・使用温度等の使用条件が異なってい るために，変位性能の指標としてこれまで使用している圧電定 数 $\left(d_{33}\right)$ が，必ずしも実使用条件での変位性能を表していな いことが分かってきた。例えば，Zhang らは，荷重の増加に 従い $d_{33}$ が減少することを示している5)。 また, Saito は印加電 圧の増加に伴い $d_{33}$ は増加するとしている豆. 更にはYamamotoはPZTへ予荷重を印加した状態では分極反転が生じて 電気機械結合係数が低下する7) としている。これまでの新しい PZT 材料の変位性能評価は, 実際の積層アクチュエーターを 作製してその变位を測定していた。しかし多大な時間と費用を 必要とするために効率的な材料開発ができなかった。

そこで最近では，テストピースの変位を測定する技術の検討 がされるようになったが，必ずしも積層アクチュエーターの実 使用条件で行われてはいない。例えば, Kuriyamaらは， $5 \times 5 \times 20 \mathrm{~mm}$ のテストピースを専用に作製し，荷重を印加し ていない状態の変位を測定している8)。なた Tani らは $\phi 15$, $t=0.5 \mathrm{~mm}$ のペレットに扔いて0.1 $\mu \mathrm{m}$ レベルの変位測定を実 施しているものの，測定周波数が $0.1 \mathrm{~Hz}$ という低周波に限定 されている99.

積層アクチュエーターの構成部品であるペレット1枚の変 位を，積層アクチュエーターと同様の動的条件において直接測 定できるようにすることは，PZT 材料の組成検討を効率的に 行えるようになる。そこで，本研究ではまず，ペレット1枚 での動的微小变位の測定方法について検討した10)。次に，こ の装置を用いてさまざなな圧電特性を有する PZT ペレットの 変位を色々な条件に打いて測定し, 従来使用してきた圧電特性 との関係を考察した。それにより，特性の優れた PZT 材料を 効率的に創製することが可能になると考えている.

\section{2. 実験方法}

微小変位測定用の PZT ペレット保持治具及びレーザー変位
計測装置 (laser doppler vibration measurement system) の概 念図を図 1に示す。ペレット保持治具は変形丕みによる共振な どから生ずる変位測定誤差をできるだけ抑えるために，剛性の 十分高いフレーム構造とした。 上下面に $\mathrm{Ag}$ ペーストを印刷後 分極処理したペレットを，ペレットと直径の等しい金属製の電 極端子にはさみ，フレーム上部のネジによりペレットを締め付 けて 0 27.7 MPa の範囲で予荷重を加えた。予荷重を加えな い上きは, 締め付けネジを用いずペレット上下の金属端子のみ とした，金属端子にはリード線を接続し，発振器に接続された 電源により駆動電王を加えた。電源の出力電圧幅は $800 \mathrm{~V}$, 出 力範囲はー $400 \sim 400 \mathrm{~V}$ の AC の需点をオフセットすることに より，片振り電压を出力することができる。ペレット厚みが $0.5 \mathrm{~mm}$ であるために, この研究ではペレット $1 \mathrm{~mm}$ 当たりに 印加された電圧として表現すると, 電圧幅は $1600 \mathrm{~V}$, 出力範 囲はー800〜 $800 \mathrm{~V}$ ，オフセットは $0 \sim 800 \mathrm{~V}$ となる. 周波数は, 6 150 Hzの正弦波とした。 今回の検討では, オフセットを $800 \mathrm{~V}$ と $400 \mathrm{~V}$ の 2 種類選択した. つまりペレットに印加され る電圧は， $0 \sim 1600 \mathrm{~V}$ と $-200 \sim 1200 \mathrm{~V}$ の種類となる。印加 電圧の変化に伴う上部金属端子面の上下位置変化量を変位量と した. ペレット装着治具の平行度を高めかつフレームの剛性を 高めることにより圧縮時のペレットへの偏荷重発生を抑制した ことと, これらの装置を防振台上に設置し，床のコンクリート が周囲から切断されて島状になったフローティングフロア構造 等の工夫により，このレーザー変位装置の分解能は $1 / 100 \mu \mathrm{m}$ を確保した。

圧電特性と変位との関係を調査するために，表１に示す７ 種類の $\mathrm{PZT}$ ペレットのさまざまな条件に抢けるペレット変位 を測定した。ペレット寸法は, 直径 $15 \mathrm{~mm}$ 厚さ0.5 mm であ る. 径方向の電気機械結合係数 $\left(K_{\mathrm{p}}\right)$ と比誘電率 $\left(\varepsilon_{33} \mathrm{~T} / \varepsilon_{0}\right)$ はペレットにて，インピーダンスアナライザー (HP4194A) を用いた共振反共振法により $1 \mathrm{kHz}$ にて測定した。 $4 \mathrm{~mm}$ 角, 長さ15 mm の角柱状テストピースにより縦方向の電気機械結 合係数 $\left(K_{33}\right)$ を測定した後に, 歪みゲージを取り付けてヤン グ率 $\left(Y_{33}{ }^{\mathrm{E}}\right)$ を測定し，(1)式により圧電定数 $\left(d_{33}\right)$ を算出し た.

$$
d_{33}=K_{33} \cdot\left(\varepsilon_{33}{ }^{\mathrm{T}} / Y_{33}{ }^{\mathrm{E}}\right)^{1 / 2}
$$




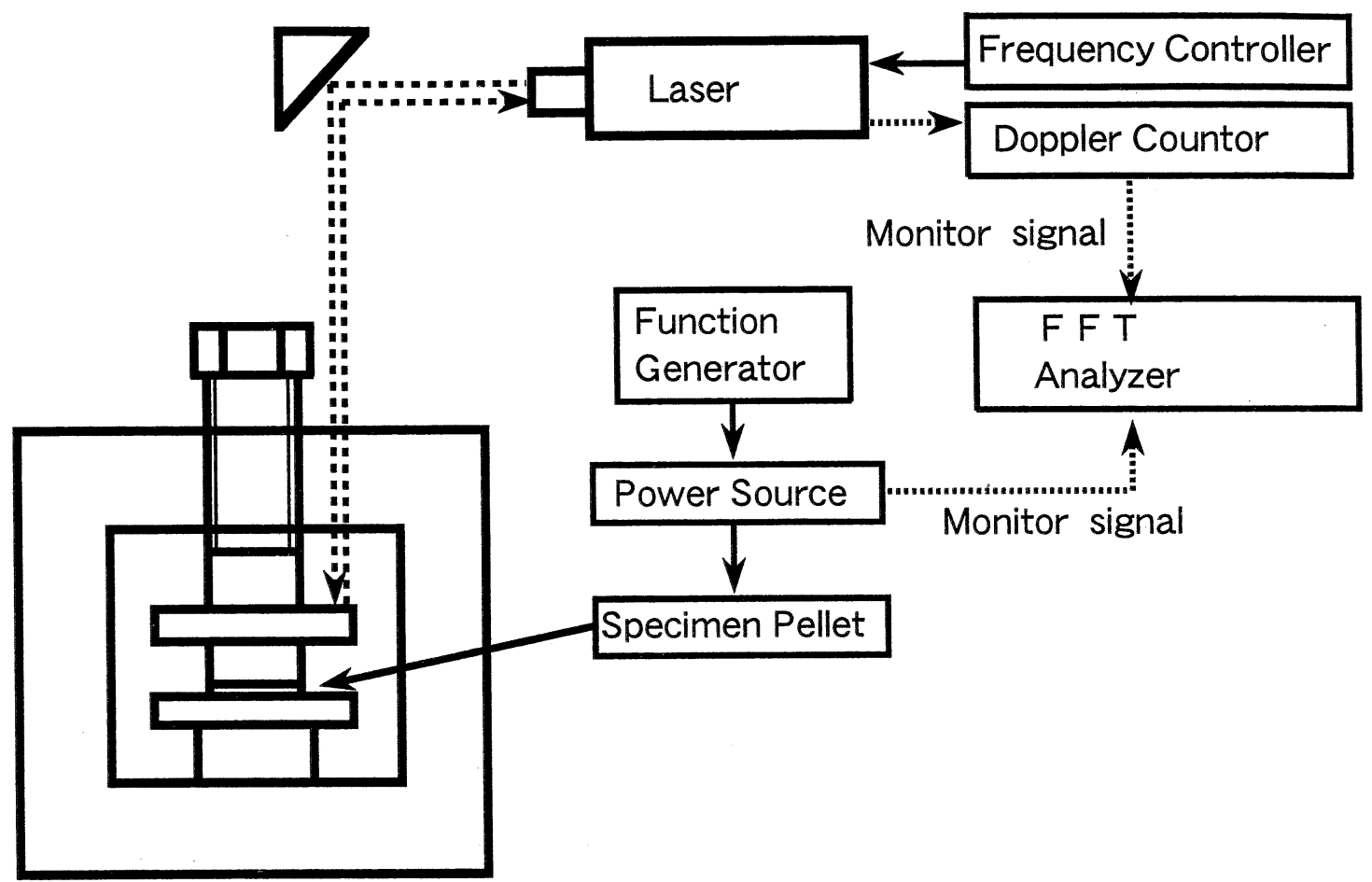

Fig. 1. Schematic diagram of the displacement measurement system which can change the conditions under various driving conditions, pre-load and driving voltage.

Table 1. Initial Characteristics of PZT Samples for Testing

\begin{tabular}{|c|c|c|c|c|c|c|c|}
\hline & A & $\mathrm{B}$ & C & D & $E$ & $\mathrm{~F}$ & $\mathrm{G}$ \\
\hline $\mathrm{d}_{33}\left(\times 10^{-12} \mathrm{~m} / \mathrm{V}\right)$ & 670 & 659 & 603 & 588 & 524 & 497 & 423 \\
\hline$k p(\%)$ & 71.0 & 64.3 & 66.7 & 65.1 & 65.0 & 65.6 & 63.2 \\
\hline$\varepsilon_{33^{\top} / \varepsilon} 0$ & 3700 & 4420 & 3590 & 3600 & 3200 & 2620 & 2250 \\
\hline $\mathrm{Qm}$ & 65 & 61 & 71 & 68 & 65 & 71 & 72 \\
\hline Tc $\left({ }^{\circ} \mathrm{C}\right)$ & 220 & 134 & 208 & 196 & 244 & 244 & 320 \\
\hline $\mathrm{E} c(\mathrm{~V} / \mathrm{mm})$ & 960 & 650 & 700 & 1030 & 1070 & 1050 & 1090 \\
\hline Grain size $(\mu \mathrm{m})$ & 6.8 & 4.8 & 2.5 & 4.0 & 5.5 & 3.1 & 3.7 \\
\hline $\begin{array}{l}\text { Bending Strength } \\
(\mathrm{MPa})\end{array}$ & 68.5 & 53.2 & 60.0 & 63.8 & 64.5 & 53.1 & 50.6 \\
\hline
\end{tabular}

ワー回路を用いて測定した $D-E$ ヒステリシス線図より求め た。

今回測定した 7 種類のサンプルは $d_{33}$ が広く分布しており, 駆動電王幅 ·オフセット・駆動周波数 - 予荷重が変位性能に与 える影響について調べた。

\section{3. 結果と考察}

$3.1 d_{33}$ と変位との関係

表 2 , 図 2 に予荷重を加えない場合のペレット1枚の変位 量を示す。ペレットへの印加電圧は, 正電圧のみの0〜1600 V 駆動と, 負電圧駆動のー400〜 $1200 \mathrm{~V}$ の結果を示した. 正 電圧駆動条件においては， $d_{33}$ と変位との間には相関性が見ら れないが，負電圧駆動の場合には比較的相関性が向上した。 た, サンプル A, B， C，Dのように正電圧駆動に比べて負電圧
駆動のときに变位が著しく増大するサンプルがあった。

$K_{33}$ の測定には角柱テストピースを専用に作製しなければな らないが，ペレットの圧電特性と変位性能との間に相関性があ れば，材料組成検討にとって効率的である。（1)式の変形を考 えると, $Y_{33} \mathrm{E}$ は一定であるから省略し, 真空の誘電率 $\left(\varepsilon_{0}\right)$ は定数であるから追加することができるとすれば(1)式は (2) 式のように变形できる.

$$
d_{33} \propto K_{33} \cdot\left(\varepsilon_{33}{ }^{\mathrm{T}} / \varepsilon_{0}\right)^{1 / 2}
$$

ここで, $K_{33}$ に変えてペレットにより測定できる径方向の電 気機械結合係数 $\left(K_{\mathrm{p}}\right)$ を使用した $(3)$ 式が成り立つとすれば都 合が良い。

$$
d_{33} \propto K_{\mathrm{p}} \cdot\left(\varepsilon_{33} \mathrm{~T} / \varepsilon_{0}\right)^{1 / 2}
$$

そこで, 表 1 と表 2 より $d_{33}$ と $K_{\mathrm{p}} \cdot\left(\varepsilon_{33}{ }^{\mathrm{T}} / \varepsilon_{0}\right){ }^{1 / 2}$ の関係を表 したものが図 3 である。図 3 から分かるように両者には相関 
Table 2. The Culculated Value from Electromechanical Coupling Factor $\left(K_{\mathrm{p}}\right)$ and Relative Dielectric Constant $\left(\varepsilon_{33}{ }^{\mathrm{T}} / \varepsilon_{0}\right)$. Displacement Properties under the Change of Voltage from Plus to Minus

\begin{tabular}{|c|c|c|c|c|c|c|c|}
\hline & $A$ & B & $\mathrm{C}$ & $D$ & $E$ & $F$ & $\mathrm{G}$ \\
\hline $\mathrm{Kp} \cdot\left(\varepsilon_{\left.33^{\top} / \varepsilon_{0}\right)^{1 / 2}}\right.$ & 41.3 & 42.7 & 39.5 & 39.1 & 36.7 & 33.5 & 30.0 \\
\hline Displacement & \multirow[b]{2}{*}{0.60} & \multirow[b]{2}{*}{0.55} & \multirow[b]{2}{*}{0.52} & \multirow[b]{2}{*}{0.52} & \multirow[b]{2}{*}{0.54} & \multirow[b]{2}{*}{0.45} & \multirow[b]{2}{*}{0.47} \\
\hline $0 \sim 1600 \mathrm{~V}$ & & & & & & & \\
\hline$-400 \sim 1200 \mathrm{~V}$ & 0.90 & 0.82 & 0.73 & 0.63 & 0.65 & 0.54 & 0.53 \\
\hline increase ratio(\%) & 23 & 33 & 29 & 20 & 17 & 17 & 12 \\
\hline
\end{tabular}

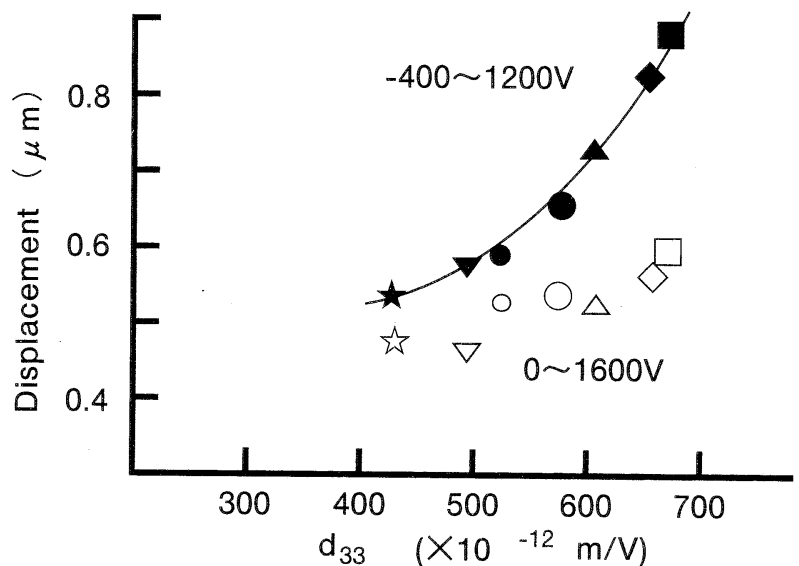

Fig. 2. Relationship between $d_{33}$ and displacement for samples, $\mathrm{A}(\square, \boldsymbol{\square}), \mathrm{B}(\diamond, \bullet), \mathrm{C}(\triangle, \boldsymbol{\Delta}), \mathrm{D}(\bigcirc, \boldsymbol{\bullet}), \mathrm{E}(0, \bullet), \mathrm{F}(\nabla, \boldsymbol{\nabla})$, $\mathrm{G}(\hat{\mathrm{s}}, \star)$

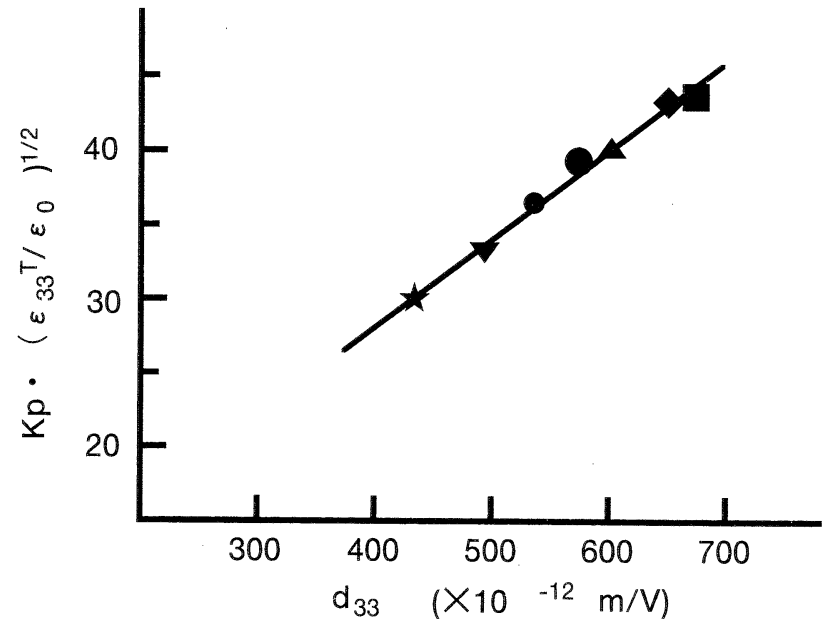

Fig. 3. Relationship between $d_{33}$ and $K_{\mathrm{p}} \cdot\left(\varepsilon_{33} \mathrm{~T} / \varepsilon_{0}\right)^{1 / 2}$.

が高く，K$K_{33}$ の代りに $K_{\mathrm{p}}$ が使用できると言える。したがっ て, $d_{33}$ の代用として $K_{\mathrm{p}} \cdot\left(\varepsilon_{33}{ }^{\mathrm{T}} / \varepsilon_{0}\right)^{1 / 2}$ を用いることが可能とい える. そこで, 図 2 の負電圧变位と $K_{\mathrm{p}} \cdot\left(\varepsilon_{33} \mathrm{~T} / \varepsilon_{0}\right) 1 / 2$ との関係 は図 4 のようになり図 2 々同様の相関傾向がみられる。以上 の結果より，ペレット変位をペレットの電気特性で表すことが 可能と考える.

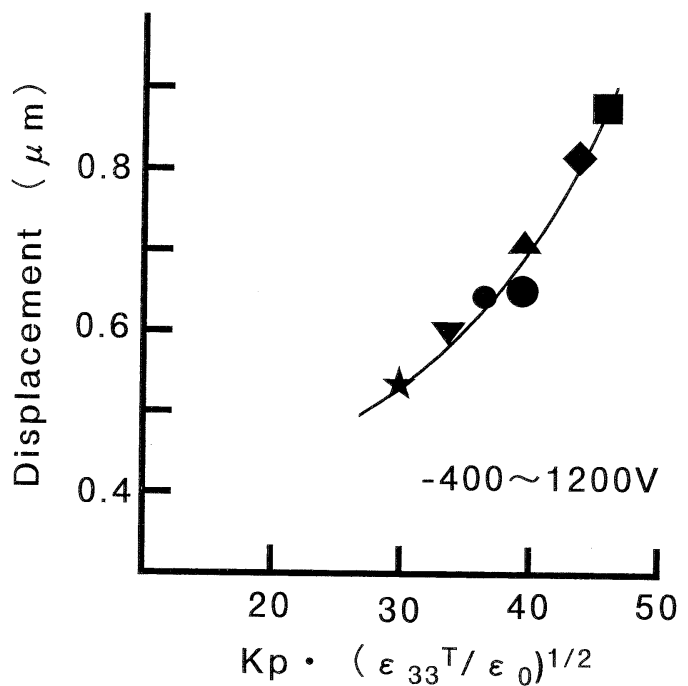

Fig. 4. Relationship between $K_{\mathrm{p}} \cdot\left(\varepsilon_{33} \mathrm{~T} / \varepsilon_{0}\right)^{1 / 2}$ and displacement.

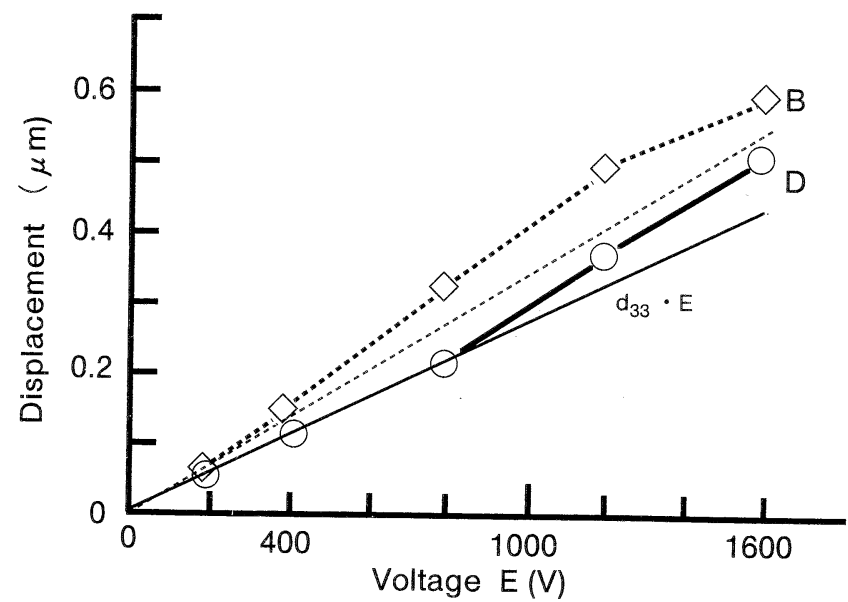

Fig. 5. The influence of driving voltage on displacement for samples $\mathrm{B}(\diamond)$ and $\mathrm{D}(\bigcirc)$.

\section{2 印加電圧の幅と変位との関係}

図 5 にサンプル B と D の, 正電圧幅を变化させたときの変 位と, 圧電定数と電圧 $E$ との積より推察される変位の計算値 $\left(d_{33} \cdot E\right)$ を示す. $d_{33}$ の大きいサンプル B では $400 \mathrm{~V}$ 以上の 電王印加において, 計算值を上回った。一方 $d_{33}$ の小さいサン 
プル D では $800 \mathrm{~V}$ までは線形性を示した。圧電材料の非線形 性は90度分極反転に起因すると言われているので，サンプル Bの変位には比較的低電圧より 90 度分極反転の成分が寄与し てくるといえる.これに対して，サンプルDにおいては，比 較的高電圧から90度分極反転の成分が変位に寄与してくると いえる.

サンプル B, D, F, G における電圧オフセット幅に対する変位 量の変化を図 6 に示す．正電圧から負電圧側へオフセットする に従って，変位量は連続的に増加している。

表 2 で示した, 抗電界 $E_{\mathrm{c}}$ と正負電圧印加時の变位の増加率 との関係を図 7 に示す。 $E_{\mathrm{c}}$ が小さいほど変位の増加率が大き いことが分かる．圧電材料に負電圧を印加すると， $E_{\mathrm{c}}$ 付近て 急激に縮み， $E_{\mathrm{c}}$ で極小となる。したがって $E_{\mathrm{c}}$ の比較的小さい 材料に負電圧を印加すると， $E_{\mathrm{c}}$ 付近での急激な縮みが正電圧 変位に加えられるために, 変位増加率が大きくなると考えられ る.

$d_{33}, K_{\mathrm{p}}$ 等の王電特性の測定は共振反共振法を用いた数ボル トの交流における測定值である.今回のような数百ボルトの電 圧を印加する場合は，分極反転や負電圧オフセットと $E_{\mathrm{c}}$ との 関係により，材料ごと測定条件ごとに変位が異なることに注意 しなければならない。

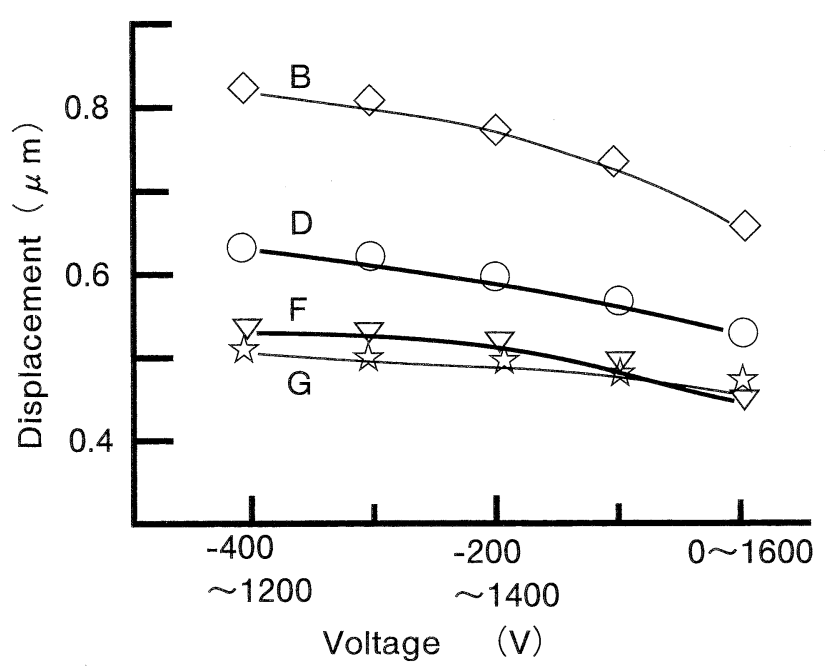

Fig. 6. Relationship between driving voltage and displacement of samples, $\mathrm{B}(\diamond), \mathrm{D}(\bigcirc), \mathrm{F}(\nabla)$ and $\mathrm{G}(\hat{\varsigma})$.

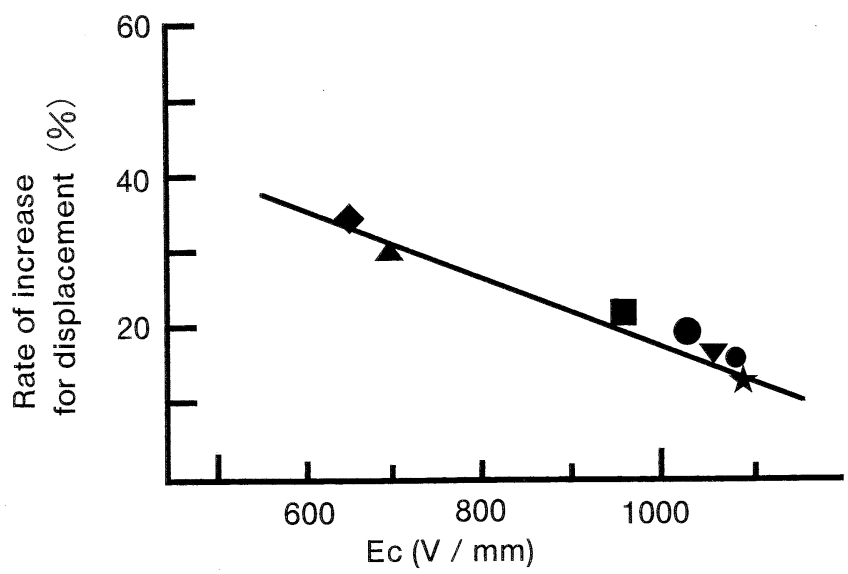

Fig. 7. Relationship between coercive field $\left(E_{\mathrm{c}}\right)$ and the rate of increase for displacement of various samples.

\section{3 印加電圧の周波数と変位との関係}

図 8 にサンプル D における变位の電圧周波数及び予荷重依 存性を示す。予荷重の大きさにかかわらず, 周波数が $6 \mathrm{~Hz}$ か ら150 Hzへ増加するにつれて変位は減少した。予荷重を加え ない場合の $6 \mathrm{~Hz}$ から $100 \mathrm{~Hz}$ の変位の低下率は $40 \%$ ，予荷重 $27.7 \mathrm{MPa}$ の場合では30\%程度となり，予荷重の大きさにより 変位の電圧周波数依存性は異なった。図 9 には予荷重 27.7 $\mathrm{MPa}$ の場合の電圧周波数の増加に伴う変位と残留分極 $P_{\mathrm{r}}$ との 関係を示した。変位量は残留分極量 $P_{\mathrm{r}}$ と関係が深いことが分 かり，電圧周波数の増加に伴う残留分極量の減少により，変位 量が減少すると考える.

以上の結果より，ペレット 1 枚の動的変位量を測定できる ことを確認した

\section{4 予荷重の変位に及ぼす影響}

印加電圧の周波数を $10 \mathrm{~Hz}$ ，印加電圧を-400 $1200 \mathrm{~V}$ とし たときの，変位の予荷重依存性を図10に示す。サンプルによっ て変位低下率の荷重依存性が異なり, その傾向からサンプル Dのように, 予荷重の増加に伴い変位低下するが，高荷重域 では変位を保つもの, サンプル B, F, G の上うに, 予荷重の増 加に伴って変位低下するものの二つのグループに分けられる.

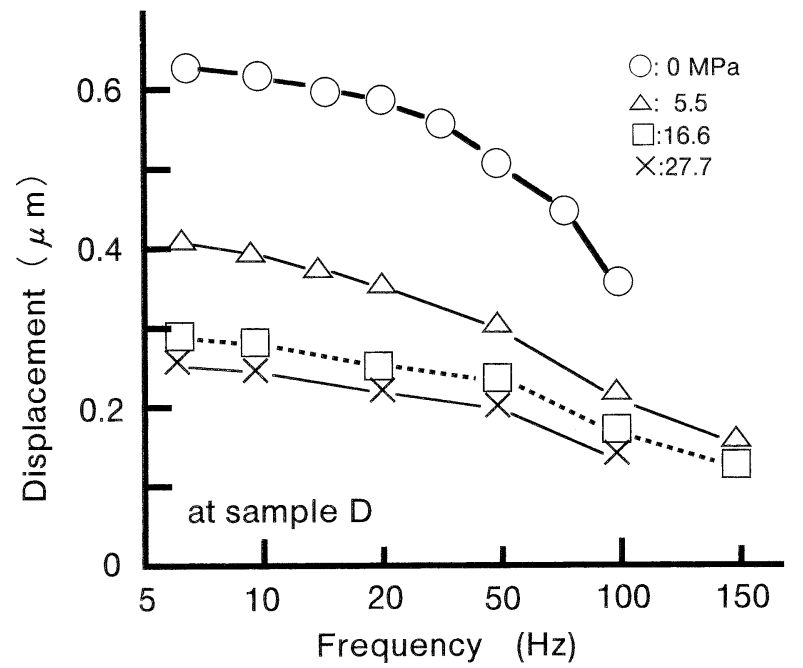

Fig. 8. The influence of frequency on displacement for sample D.

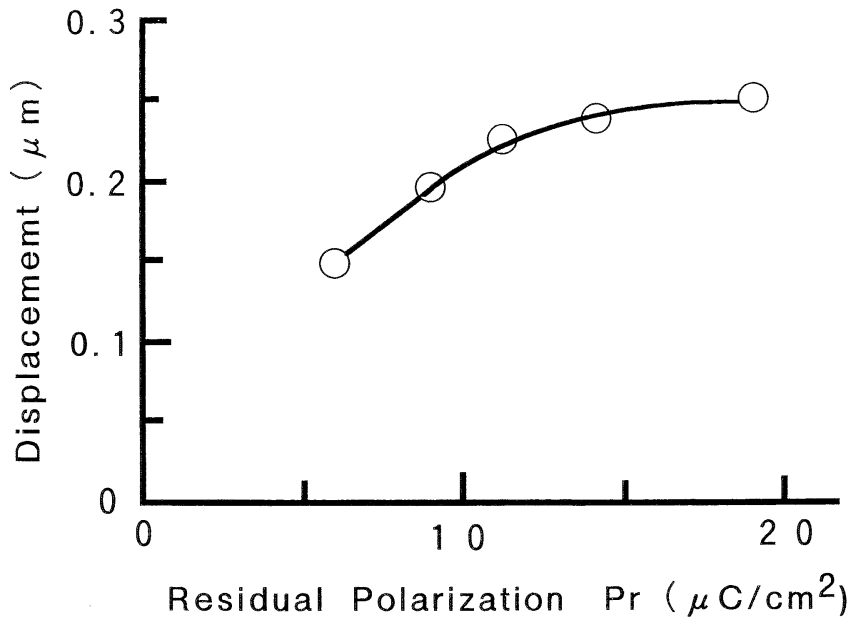

Fig. 9. Relationship between residual polarization $\left(P_{\mathrm{r}}\right)$ and displacement of sample D. 


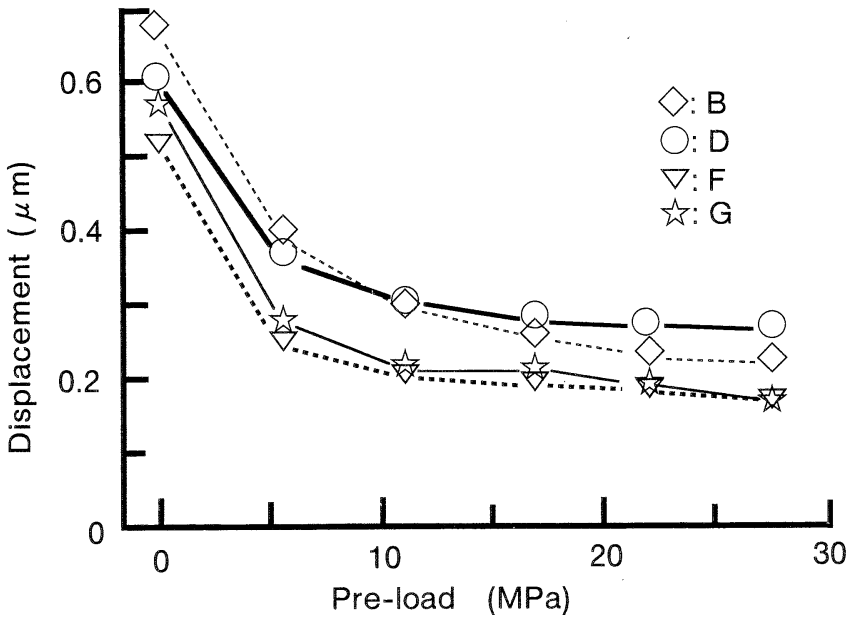

Fig. 10. The influence of pre-load on displacement under the driving voltage from -200 to $600 \mathrm{~V}$ at $10 \mathrm{~Hz}$.

サンプル D は, 今回実験した 7 種類のサンプルの中では $d_{33}$ は中間に位置し予荷重を加えない場合の変位は図 2 から分か るように, 他の材料の傾向から突出してはいない。しかし, 図 5 に打けるサンプル D の变位の非線形性が比較的高電圧より 発生することから考えて, 変位に抢ける分極反転成分の割合が 少ないといえる.PZT 材料に予荷重を加えた場合分極反転が 生ずる7)ことから考えて, サンプル D においてはその影響が小 さいために, 高荷重域まで変位を保つことができたと考えられ る。

従来の研究において変位量は予荷重のほとんど加わらない状 態で比較されていた。しかし，今回予荷重を加えた状態での変 位量を測定することが可能となった。予荷重を加えない場合に は, 圧電特性と負電圧印加変位とは, 比較的良い相関が得られ たが，予荷重を加えた場合は，分極反転や機械的剛性等も含め た，材料組成の影響も大きくなることが考えられる．例えば， アクセプターを添加した組成においては，变位の荷重依存性が 小さくなる例がある12)。

\section{4. 結 論}

数百ボルトの電圧, 6 $100 \mathrm{~Hz}$ の周波数範囲, 予荷重 0 $27 \mathrm{MPa}$ という実用域の条件において, ペレット1枚の変位量 を $1 / 100 \mu \mathrm{m}$ の精度での測定が可能となった.

予荷重を加えない場合, ペレットへの印加電圧の正負・幅に より, 種々の PZT 材料同士の変位量の傾向は異なったが, 負 電圧を用いた变位は，電気特性との相関が比較的良かった。 た, ペレットへの印加電圧の周波数増加に伴う残留分極量の減 少により，変位量が減少すると考えられる。

しかし, 予荷重を加えた場合の変位量は, ペレットの電気特 性だけでは相関づけられず, 分極反転や機械的剛性等も含めた 材料組成の影響も大きくなると考えられる.

以上の結果より，積層アクチュエーターの構成部品であるぺ レット 1 枚の変位を, 積層アクチュエーターと同様の動的条 件に抢いて，抢抢よそ測定できるようになった。

これにより，PZT 材料の組成検討を効率的に行えるように なると考えている。

\section{文献}

1) Y. Yokoya, K. Asami, T. Hamajima and N. Nakashima, Toyota Electronic Modulated Suspension (TEMS) System for the 1983 Soarer, SAE Paper 840341 (1984).

2）深見 彰, 矢野正行, 徳田 寛, 黄木正美, 木津龍平, 自動 車技術会学術講演会前刷集（1990）pp. 1373-79.

3) A. J. Bell, "Piezoelectric and Electrostrictive Materials for Actuators," Actuator '90 Conference (1990) pp. 150-55.

4) T. Sakai, M. Ishikiriyama and R. Shimazaki, Jpn. J. Appl. Phys., 31, 3051-54 (1992).

5) Q. M. Zhang, J. Zhao, K. Uchino and J. Zheng, J. Mater. Res., 12, 226-34, (1997).

6) S. Saito, Jpn. J. Appl. Phys., 34, 5313- 19 (1995).

7) T. Yamamoto, Jpn. J. Appl. Phys., 30, 2256-59 (1991).

8) A. Kuriyama, K. Nomura, K. Hirota and T. Ikeda, Jpn. J. Appl. Phys., 31, 3085-89 (1992).

9) T. Tani, N. Watanabe, K. Takatori and S. Hori, Jpn. J. Appl. Phys., 33, 5352-55 (1994).

10）酒井武信，島崎龍司，日本セラミックス協会年会講演予稿集 (1993) p. 327.

11）岡崎清, “セラミック誘電体工学, 第 3 版” 学献社 (1983) p. 325.

12) T. Sakai, Y. Terai, M. Ishikiriyama, Jpn. J. Appl. Phys., 34, 5276-73 (1995). 